\title{
A Kinetic Study of Silver Electrodeposition Onto Pt Ultramicroelectrodes From Amoniacal Solutions
}

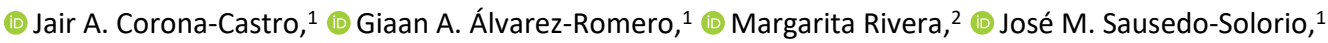 \\ Clara H. Rios-Reyes, ${ }^{3}$ (1) Luis H. Mendoza-Huizar ${ }^{1, *}$
}

\footnotetext{
1 Universidad Autónoma del Estado de Hidalgo. Academic Area of Chemistry. Carretera Pachuca-Tulancingo Km. 4.5 Mineral de la Reforma México

2 Instituto de Física, Universidad Nacional Autónoma de México, Ciudad de Mexico, 04510, México

3 Universidad La Salle Pachuca. Calle Belisario Domínguez 202, Centro, 42000 Pachuca de Soto, Hgo., México

* Corresponding author's e-mail address: hhuizar@uaeh.edu.mx
}

RECEIVED: April 17, $2021 \star$ REVISED: June 15, $2021 \star$ ACCEPTED: June 18, 2021

\begin{abstract}
A kinetic study of the Ag electrodeposition onto Pt ultramicroelectrodes of 10, 15 and $25 \mu \mathrm{m}$ of diameter from an aqueous solution containing $\mathrm{AgNO}_{3} 1 \mathrm{mM}+\mathrm{NH}_{4} \mathrm{NO}_{3} \mathrm{O} .1 \mathrm{M}$ was conducted at overpotential conditions through potentiostatic studies. The analysis of the current density transients indicates the existence of two 2D nucleation and growth processes previous to the 3D nucleation and growth process.
\end{abstract}

Keywords: silver, platinum, ultramicroelectrode, 2D nucleation, kinetics.

\section{INTRODUCTION}

S ILVER coatings exhibit excellent electrical conductivity and good anti-wear property in bearings and electronic components, as well as resistance to high temperatures and corrosion. ${ }^{[1-3]}$ These coatings are widely used on an industrial scale in high-performance technological fields belonging to electronics, electrical engineering, aeronautics, as well as in the food industry or in the artistic design of jewelery and art objects. ${ }^{[1]} \mathrm{Ag}$ coatings can be obtained by electrodeposition, since this technique allows obtaining uniform coatings with excellent quality at low-cost, and easily scalable at the industrial level. ${ }^{[2]}$ Silver has been electrodeposited on $\mathrm{Pt},{ }^{[4-12]} \mathrm{Cu},[1,2,13-17] \quad \mathrm{GCE},[5,16,18-21]$ $\mathrm{Au}^{[5,22]} \mathrm{Si},{ }^{[19,23]} \mathrm{HOPG},{ }^{[21,24]}$ and graphene, ${ }^{[4]}$ among others substrates. Plating baths based on nitrates, ${ }^{[7-13,20,23,24]}$ cyanides, ${ }^{[1,4,9,15-18,22]}$ chloride, ${ }^{[5,9,17,19]}$ bromide, ${ }^{[13]}$ and sulfates $^{[22]}$ are the most employed. In general, it has been found that the silver electrodeposition process is controlled by mass transfer and follows a progressive nucleation process. ${ }^{[7,15-22]}$ However, if the electroplating bath has chloride ions, the nucleation process of the electrodeposited silver changes to instantaneous. ${ }^{[5,9,17,19]}$ Similarly, the silver electrodeposition on silicon substrate electrodes shows a clear change on the deposition mechanism from progressive to instantaneous nucleation. ${ }^{[19,23]}$ In addition, silver nitrate plating baths are able to decrease the current density necessary to carry out silver electrodeposition. Moreover, a change in nitrates concentration in the solution allows to control the roughness of the deposit. ${ }^{[10,12,13,15,23]}$ In cyanide silver plating baths, a higher concentration of these anions causes a major energy requirement to electrodeposit silver. However, if the silver ions concentration is increased, the silver electrodeposition potential value moves to potentials that are more positive. ${ }^{[1,12,14,16]}$ For a low silver concentration it has been reported a transition 2D-2D and 2D-3D on GCE substrates, while that at higher concentration it is possible to get a $3 \mathrm{D}$ growth. Also, Nevers and others have reported that the use of ultrasound during silver plating can change significantly the microstructure and morphology of the silver deposits without the use of chemical additives. ${ }^{[8]}$ Typically, silver electrodeposition involves working electrodes with a diameter higher than 1 $\mathrm{mm}$. On this kind of electrodes different kinetic controls and different system behavior have been reported. ${ }^{[1-24]}$

On the other hand, microelectrodes or ultramicroelectrodes (UMEs), offer unique electrochemical characteristics. These include, in addition to their extreme small 
size, minimization of solution resistance effects and rapid response times. The electrochemical behavior of microelectrodes can appear markedly different from that observed at conventionally sized electrodes. UMEs have proven to be a convenient tool for electrodepositing studies, since their use allows obtaining a process controlled by diffusion. Thus, their small dimensions allow the formation and growth of a small number of nuclei or even individual nuclei, reducing the interference between them. In addition, the effects of small changes on the surface state of the substrate can be detected in electrochemical measurements easily. ${ }^{[25,26]}$ However, only a few number of electrodeposition studies have been carried out using UMEs, despite the reported advantages compared to conventional electrodes. ${ }^{[25-29]}$ Peña et al. ${ }^{[25]}$ conducted a study of the electrochemical nucleation and growth of $\mathrm{Ag}$ on polycrystalline Pt microelectrodes and carbon fibers by using voltammetric and potentiostatic techniques in aqueous solutions with and without supporting electrolyte. They reported different Ag electrocrystallization modes, which are easily detected by voltammetric and potentiostatic methods by using microelectrodes. Additionally, they found that parameters, such as overpotential and the kind of supporting electrolyte, modify the morphology of the silver electrodeposits. In other work reported by Duo et al. the $\mathrm{Ag}$ electrodeposition on carbon microelectrodes showed that the electrochemical treatment of the electrode, the absence of supporting electrolyte and a particular range of higher potentials affect the growth process. ${ }^{[26]}$ To the best our knowledge, there are few reports studying the electrodeposition process of silver onto platinum UMEs. Therefore, the purpose of the present study is determining the influence of the Pt-UME diameter in the kinetic parameters values related to the silver electrodeposition process from ammoniacal solutions.

\section{METHODOLOGY}

$\mathrm{Ag}$ electrodeposits were obtained from an aqueous solution containing $1 \mathrm{mM} \mathrm{AgNO} 3+0.1 \mathrm{M} \mathrm{NH}_{4} \mathrm{NO}_{3}$. All solutions were prepared using analytic grade reagents with ultra pure water (Millipore-Q system) and were deoxygenated by bubbling $\mathrm{N}_{2}$ for 15 minutes before each experiment. A 3-compartment electrochemical cell was used in the electrochemical experiments. $\mathrm{An} \mathrm{Ag} / \mathrm{AgCl}$ and graphite bar served as the reference and counter electrode, respectively. Platinum ultramicroelectrodes (Pt-UMEs) of 10 (Pt-UME-10), 15 (Pt-UME-15) and 25 (Pt-UME-25) $\mu \mathrm{m}$ de diameter were used as working electrode and polished and ultrasonicated cleaned before each experiment. The control of the experiments was carried out through an Epsilon potentiostat connected to a personal computer, through the BASi Epsilon EC software.

\section{RESULTS AND DISCUSSION}

Figure 1. shows typical cyclic voltammograms obtained from the $1 \mathrm{mM} \mathrm{AgNO}+0.1 \mathrm{M} \mathrm{NH}_{4} \mathrm{NO}_{3}$ system onto Pt-UMEs with different diameter. Note that the voltammogram recorded onto the Pt-UME-10 exhibits a higher current density, in comparison to the Pt-UME-15 and PtUME-25 electrodes. This is because the radial diffusion greatly enhances mass transport to and from the electrode surface as the UME size diminishes. As a result, the current density recorded onto this ultramicroelectrode is related to a bigger radial diffusion in comparison to the other electrodes.

Figure 2. shows a set of typical cyclic voltammograms obtained from the Pt-UME-10/1 $\mathrm{mM} \mathrm{AgNO}_{3}+0.1 \mathrm{M} \mathrm{NH}_{4} \mathrm{NO}_{3}$ system at different scan rates. During the direct scan, it is possible to note the formation of a peak A. Also, it is reported a cyclic voltammogram obtained from the PtUME-10/0.1 $\mathrm{M} \mathrm{NH}_{4} \mathrm{NO}_{3}$ system. The comparison between the cyclic voltammograms obtained from these systems indicates that peak A can be associated with the silver electrodeposition. Similar results were found for the cyclic voltammograms recorded onto the Pt UMEs of 15 and 25 $\mu \mathrm{m}$ of diameters, not shown. In order to find the type of control limiting, of the electrodeposition process, related to peak $A$ in the different systems; the maximum current density $\left(j_{p}\right)$ value associated with each peak was plotted as a function of $v^{1 / 2}$, see Figure 3. A linear relationship was found indicating a diffusional-controlled process ${ }^{[12,13]}$. The diffusion coefficient values were evaluated from BerzinsDelahay's equation ${ }^{[30]}$

$$
j_{\mathrm{p}}=0.6105\left(\frac{F^{3}}{R T}\right)^{1 / 2} n^{3 / 2} D^{1 / 2} C_{0} v^{1 / 2}
$$

From the slope of the $j_{\mathrm{p}}$ vs $v^{1 / 2}$ plot it is possible to evaluate the diffusion coefficient values, these values were

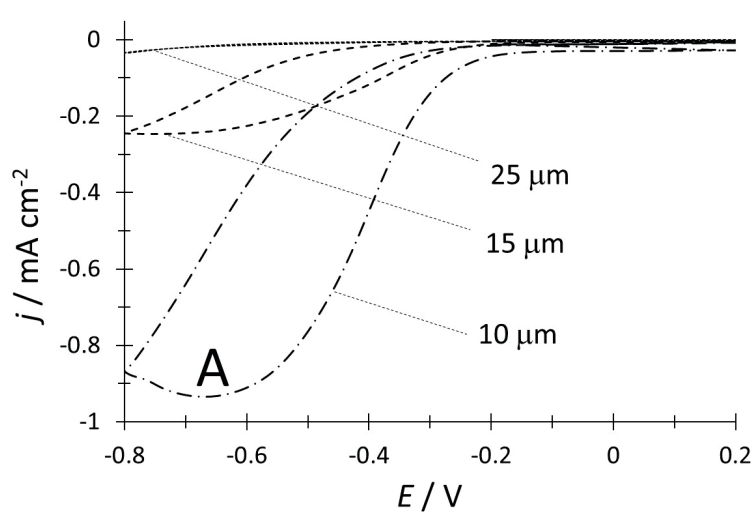

Figure 1. Cyclic voltammograms obtained from the plating bath $1 \mathrm{mM} \mathrm{AgNO}_{3}+0.1 \mathrm{M} \mathrm{NH}_{4} \mathrm{NO}_{3}$ at $80 \mathrm{mV} \mathrm{s}^{-1}$ onto platinum ultra microelectrodes of different diameter. 
$8.01 \times 10^{-5} \pm 5.96 \times 10^{-7}, 1.21 \times 10^{-6} \pm 1.24 \times 10^{-8}$ and $0.6 \times 10^{-6} \pm 1.81 \times 10^{-9} \mathrm{~cm}^{2} \mathrm{~s}^{-1}$, for Pt-UME-10, Pt-UME-15 and Pt-UME-25, respectively. Here, it is interesting to mention that at an inlaid disk microelectrode the steady state current is defined by the Saito's equation as $I_{s s}=4 n F S C_{0} D / r_{0}$, where the electrode surface is $S=\pi r_{0}^{2}$ and $r_{0}$ is the radius of the microelectrode. ${ }^{[31]}$ Thus, it is possible to define $I_{s s}=4 n F C_{0}\left(D / r_{0}\right)$, where $\left(D / r_{0}\right)$ may be considered as an apparent diffusion coefficient and $D_{\text {app }} r_{0}=D$. However, note that the values of the diffusion coefficient for Pt-UME-15 and Pt-UME-25 are $1.5 \%$ and $0.75 \%$ in comparison to the obtained for Pt-UME-10; but the difference between the radii electrodes of Pt-UME-15 and Pt-UME-25 are 1.5 and 2.5 times, respectively, in comparison to Pt-UME-10. Thus, the apparent diffusion coefficients values, calculated in the present work, does not follow the relationship $D=D_{\text {app }} r_{0}$. In this sense, it has been reported that as the electrode size is decreased there is an inequality and $I_{s s}<4 F C_{0} D r_{0}$. Thus, there is a systematic dependence of the currents on radii. ${ }^{[32]}$ This is probably due to that at the micro-disk electrode, enhancement of the current signal results from the fact that radial diffusion becomes important, as the disk radius gets smaller. ${ }^{[34]}$ Thus, it is possible to achieve and maintain steady state currents in a relatively short experimental time. ${ }^{[33]}$ Moreover, during an electrodeposition process the microelectrode shape is changing. Thus, the expanding surface area of the growing deposit diminishes the current density on the stationary approximation, thereby providing additional depolarization, which is more significant when the electrode size is smaller. Also, as the electrode potential is cathodically scanned, there are variations on the chemical transport and electric fields during voltammetric measurements, which causes dynamic current density profiles during deposition onto a microelectrode. ${ }^{[34]}$ Thus, the above mentioned indicates that the concentration of the electroactive species on the surface is time dependent; ${ }^{[35]}$ which may cause variations

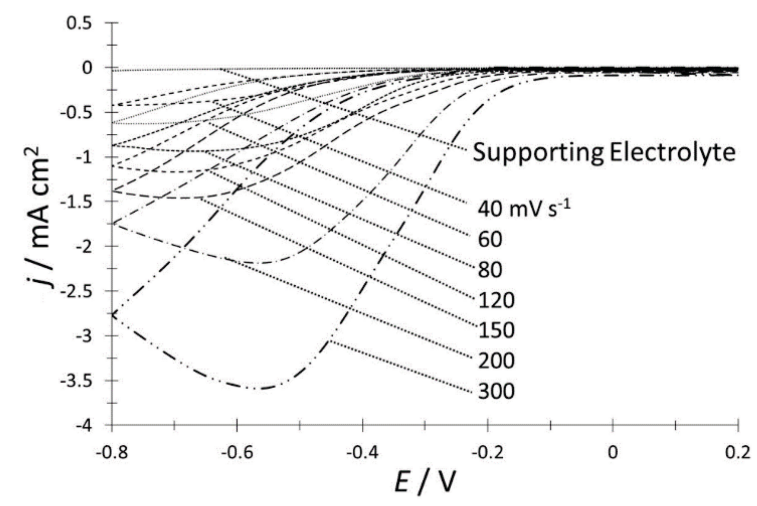

Figure 2. Cyclic voltammograms obtained from the system Pt-UME-10/ $1 \mathrm{mM} \mathrm{AgNO}_{3}+0.1 \mathrm{M} \mathrm{NH}_{4} \mathrm{NO}_{3}$ at different scan rates indicated in the Figure. on the $I_{\mathrm{ss}}$ values. Thus, the relationship $D=D_{\mathrm{app}} r_{0}$ fails to evaluate the diffusion coefficient value, when microelectrodes with different size are used during the electrodeposition process. On the other hand, observe that the values of the diffusion coefficients obtained for Pt-UME-15 and Pt-UME-25 are close to those obtained at macroelectrodes, which suggests that a planar microelectrode diffusion is reached instead of radial diffusion. ${ }^{[36,37]}$

\section{Kinetic Analysis of the 3D Nucleation and Growth Process}

Formation of new phases generally occurs through nucleation and growth mechanisms and the corresponding current density transients may provide valuable information about the kinetics of electrodeposition. A set of current density transient recorded at different potentials by a double pulse potential technique were obtained by applying an initial potential of $0.200 \mathrm{~V}$ onto the surface of the Pt-UMEs. At this potential value, the silver deposition had still not begun. After the application of this initial potential, a step of negative potential was varied on the electrode surface, in the range $[-0.340$ to -0.600$] \mathrm{V}$. Figure 4 . shows a comparison of the transients obtained at $-0.440 \mathrm{~V}$ onto the Pt-UME-10, Pt-UME-15 and Pt-UME-25 electrodes. Note that in all cases may be observed the formation of three peaks I, II and III, which may be related to different growth processes onto the electrode surface.

Observe that the current associated with peak I and II decays to zero, see inset in Figure 4., this behavior has been related to $2 \mathrm{D}$ dimensional and nucleation processes. On the other hand, the current associated with the third process (III) passes through a maximum and then approaches to the planar microelectrode limiting diffusion current. This behavior has been associated with 3D nucleation and growth processes controlled by a mass transfer reaction. ${ }^{[38,39]}$. Here, it is important to comment that the nucleation mechanism may proceed either

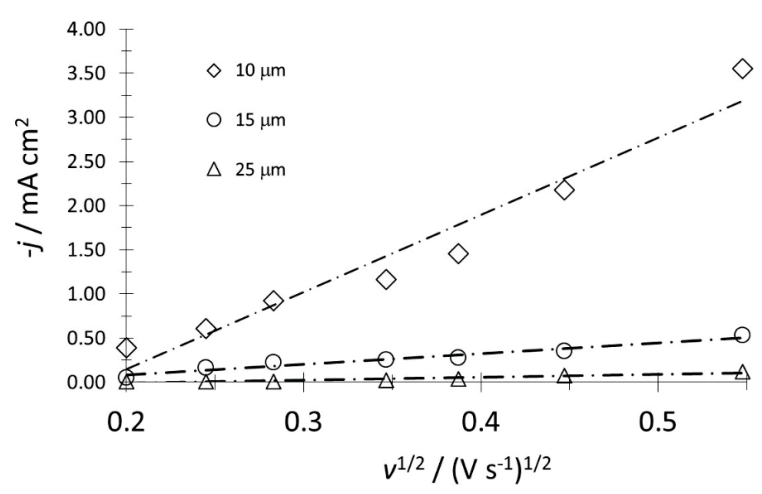

Figure 3. Plot of the experimental cathodic peak current density $\left(j_{p}\right)$ as a function of scan rate $\left(v^{1 / 2}\right)$ for Peak $A$ (see Figure 2.) at different scan rates on Pt-UMEs of 10, 15 and $25 \mu \mathrm{m}$. 


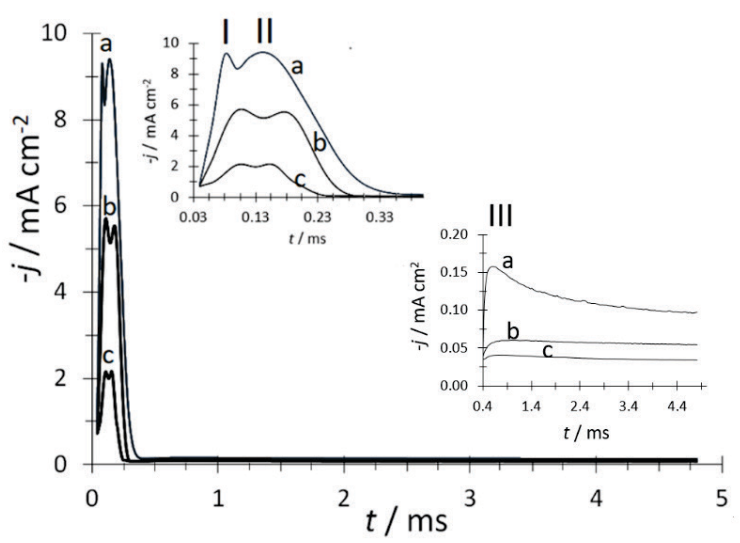

Figure 4. Experimental current density transient recorded at $-0.440 \mathrm{~V}$, during the silver electrodeposition from the plating bath $1 \mathrm{mM} \mathrm{AgNO}_{3}+0.1 \mathrm{M} \mathrm{NH}_{4} \mathrm{NO}_{3}$ system onto a) Pt-UME-10, b) Pt-UME-15 and c) Pt-UME-25. In all cases, the starting potential of $0.200 \mathrm{~V}$ was applied to the platinum electrode surface and $t=5 \mathrm{~ms}$. The insets show a close up of the full transients in two regions, at short times $(0 \leq t \leq$ $0.4 \mathrm{~s})$ and at $t \geq 0.4 \mathrm{~s}$.

instantaneously or progressively. ${ }^{[40,41]}$ The theoretical description of potentiostatic current density transients associated with $2 \mathrm{D}$ dimensional and nucleation processes for the instantaneous case is given by: ${ }^{[40,42]}$

$$
\begin{aligned}
& j_{2 \mathrm{D}-\mathrm{i}}(t)=k_{1} t \exp \left(-k_{2} t^{2}\right) \\
& k_{1}=\frac{2 \pi z F M h N_{0} K_{g}^{2}}{\rho} \\
& k_{2}=\frac{\pi M^{2} N_{0} k_{g}^{2}}{\rho^{2}} \\
& k_{1}=2 k_{2} q_{\text {nucl }}
\end{aligned}
$$

while that for the progressive case is:

$$
j_{2 \mathrm{D}-\mathrm{p}}(t)=k_{3} t^{2} \exp \left(-k_{4} t^{3}\right)
$$

where

$$
\begin{aligned}
& k_{3}=\frac{2 \pi z F M h a N_{0} k_{g}^{2}}{\rho} \\
& k_{4}=\frac{\pi M^{2} a N_{0} k_{g}^{2}}{3 \rho^{2}} \\
& k_{3}=3 k_{4} q_{\text {nucl }}
\end{aligned}
$$

In these equations $z$ is the number of electrons transferred, $F$ is Faraday constant, $M$ the molecular weight, $k_{\mathrm{g}}$ and $a$ are constant controlled by the potential, $h$ is the height, $q_{\text {nucl }}$ is the charge density associated with formation of the $2 \mathrm{D}$ deposit, and $N_{0}$ is the number density of active sites. Similarly, in a 3D nucleation and growth process controlled by a mass transfer reaction onto an UME, the current density for the instantaneous case is given by: ${ }^{27]}$

$$
\begin{aligned}
& j(t)_{3 D-i}=\left(4 z F D c r_{0}+8 n F c r_{0}^{2} D^{\frac{1}{2}} \pi^{-\frac{3}{2}} t^{-\frac{1}{2}}\right) . \\
& {[1-\exp (-N \pi k D t)] } \\
& k=\left(\frac{8 \pi c M}{\rho}\right)^{1 / 2}
\end{aligned}
$$

while that for the progressive case is: ${ }^{[27]}$

$$
\begin{aligned}
& j(t)_{3 D-p}=\left(4 z F D c r_{0}+8 n F c r_{0}^{2} D^{\frac{1}{2}} \pi^{-\frac{3}{2}} t^{-\frac{1}{2}}\right) . \\
& {\left[1-\exp \left(-0.5 A N \pi k^{\prime} D t^{2}\right)\right] } \\
& k^{\prime}=\frac{4}{3}\left(\frac{8 \pi c M}{\rho}\right)^{1 / 2}
\end{aligned}
$$

where $D$ is the diffusion coefficient of the metal ion, $c$ is the silver concentration and $r_{0}$ is the radius of the Pt-UME. Thus, considering the existence of two 2D dimensional and nucleation and growth processes and a 3D process. The total current density should be predicted by the sum of these three contributions. In this work, the transients depicted in Figure 4. were well described by:

$$
j_{T}=j_{2 \mathrm{D}-\mathrm{p}-1}(t)+j_{2 \mathrm{D}-\mathrm{p}-1 \mid}(t)+j_{3 \mathrm{D}-\mathrm{i}-\mathrm{III}}(t)
$$

where $j_{2 \mathrm{D}-\mathrm{p}-\mathrm{I}}(t)$ and $j_{2 \mathrm{D}-\mathrm{p}-11}(t)$ are the 2D progressive nucleation and growth processes due to peak I and II, respectively, and $j_{3 \mathrm{D}-\mathrm{i}-\mathrm{III}}(t)$ is the $3 \mathrm{D}$ instantaneous nucleation and growth related to peak III. Figure 5 . shows a

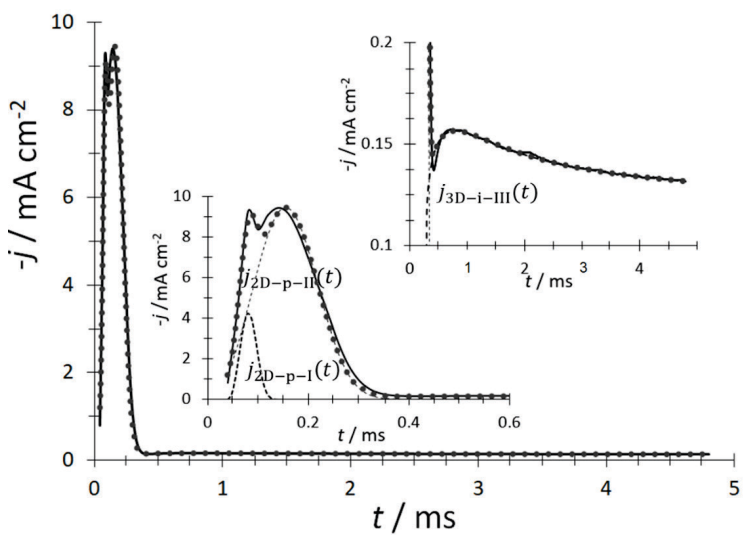

Figure 5. Comparison of an experimental current density transient $(-)$ recorded during silver electrodeposition at $-440 \mathrm{mV}$ from the Pt-UME-10/1 $\mathrm{mM} \mathrm{AgNO}_{3}+0.1 \mathrm{M} \mathrm{NH}_{4} \mathrm{NO}_{3}$ system and a theoretical transient $(\bullet \bullet \bullet)$ obtained by non-linear fit of Eq. (14). The insets show a close up of the full transients in two regions, at short times $(0 \leq t \leq 0.6 \mathrm{~s})$ and at $t \geq 0.4 \mathrm{~s}$. 
Table 1. Charge values associated with the processes I, II and III for the silver electrodeposition from the Pt-UME-x / $1 \mathrm{mM} \mathrm{AgNO} \mathrm{H}_{3}+$ $0.1 \mathrm{M} \mathrm{NH}_{4} \mathrm{NO}_{3}$ system (where $x=10,15$, and $25 \mu \mathrm{m}$ )

\begin{tabular}{|c|c|c|c|c|c|c|c|c|c|}
\hline \multirow[b]{2}{*}{$E / V$} & \multicolumn{3}{|c|}{ Pt-UME-10 } & \multicolumn{3}{|c|}{ Pt-UME-15 } & \multicolumn{3}{|c|}{ Pt-UME-25 } \\
\hline & $\begin{array}{l}\mathrm{Q}_{2 \mathrm{D}-\mathrm{p}-1} \\
\mu \mathrm{C} \mathrm{cm}^{-2}\end{array}$ & $\begin{array}{l}\mathrm{Q}_{2 \mathrm{D}-\mathrm{p}-\mathrm{II}} / \\
\mu \mathrm{C} \mathrm{cm}^{-2}\end{array}$ & $\begin{array}{l}\mathrm{Q}_{3 \mathrm{D}-\mathrm{i}-\mathrm{III}} / \\
\mu \mathrm{C} \mathrm{cm}^{-2}\end{array}$ & $\begin{array}{l}\mathrm{Q}_{2 \mathrm{D}-\mathrm{p}-1} / \\
\mu \mathrm{C} \mathrm{cm}^{-2}\end{array}$ & $\begin{array}{l}\mathrm{Q}_{2 \mathrm{D}-\mathrm{p}-\mathrm{II}} / \\
\mu \mathrm{C \textrm {cm } ^ { - 2 }}\end{array}$ & $\begin{array}{l}\mathrm{Q}_{3 \mathrm{D}-\mathrm{i}-\mathrm{III}} / \\
\mu \mathrm{cm}^{-2}\end{array}$ & $\begin{array}{l}\mathrm{Q}_{2 \mathrm{D}-\mathrm{p}-\mathrm{I}} / \\
\mu \mathrm{Cm}^{-2}\end{array}$ & $\begin{array}{l}\mathrm{Q}_{2 \mathrm{D}-\mathrm{p}-\mathrm{II}} / \\
\mu \mathrm{C \textrm {cm } ^ { - 2 }}\end{array}$ & $\begin{array}{l}\mathrm{Q}_{3 \mathrm{D}-\mathrm{i}-\mathrm{III}} / \\
\mu \mathrm{C} \mathrm{cm}^{-2}\end{array}$ \\
\hline-0.340 & 0.155 & 0.882 & 0.188 & 0.121 & 0.632 & 0.194 & 0.125 & 0.248 & 0.035 \\
\hline-0.360 & 0.172 & 0.649 & 0.174 & 0.123 & 0.578 & 0.256 & 0.171 & 0.190 & 0.053 \\
\hline-0.380 & 0.180 & 1.433 & 0.192 & 0.126 & 0.552 & 0.372 & 0.102 & 0.255 & 0.084 \\
\hline-0.420 & 0.170 & 1.433 & 0.511 & 0.124 & 0.657 & 0.409 & 0.099 & 0.274 & 0.246 \\
\hline-0.440 & 0.170 & 1.433 & 0.640 & 0.125 & 0.662 & 0.452 & 0.154 & 0.216 & 0.325 \\
\hline-0.480 & 0.142 & 1.375 & 0.934 & 0.124 & 0.673 & 0.565 & 0.162 & 0.161 & 0.436 \\
\hline-0.520 & 0.140 & 1.273 & 1.114 & 0.124 & 0.698 & 1.096 & 0.123 & 0.179 & 0.823 \\
\hline-0.540 & 0.155 & 1.380 & 1.146 & 0.128 & 0.637 & 1.096 & 0.121 & 0.201 & 0.974 \\
\hline-0.580 & 0.126 & 1.540 & 1.400 & 0.130 & 0.639 & 1.635 & 0.125 & 0.213 & 1.052 \\
\hline-0.600 & 0.120 & 1.531 & 1.662 & 0.130 & 0.644 & 1.635 & 0.123 & 0.289 & 1.204 \\
\hline
\end{tabular}

comparison of an experimental current density transient with a theoretical current transient generated by a nonlinear fitting to the experimental data by using Eq. (13). It is clear that the proposed model adequately describes the experimental current transient behavior. Similar fittings were obtained for the other experimental transients. Through these nonlinear fittings, it was possible the deconvolution and the evaluation of the charge associated with each process and the values are reported in Table 1. Note that in all cases the charges related to peaks I, II and III are larger when the Pt-UME-10 is used, which suggests a major diffusion coefficient in this system, which agrees with the results obtained from the voltammetric study.

Table 2. Potential dependence observed for the number of active nucleation sites related to the process III to the silver electrodeposition from the Pt-UME-x / $1 \mathrm{mM} \mathrm{AgNO}_{3}+$ $0.1 \mathrm{M} \mathrm{NH}_{4} \mathrm{NO}_{3}$ system (where $x=10,15$, and $25 \mu \mathrm{m}$ )

\begin{tabular}{cccc}
\hline & \multicolumn{3}{c}{$N_{0} \times 10^{7} / \mathrm{cm}^{-2}$} \\
\hline$E / V$ & Pt-UME-10 & Pt-UME-15 & Pt-UME-25 \\
\hline-0.340 & 0.0113 & 0.5893 & 1.0116 \\
-0.360 & 0.0091 & 0.8178 & 1.4126 \\
-0.380 & 0.0137 & 0.8835 & 2.1279 \\
-0.420 & 0.0104 & 0.2798 & 6.6887 \\
-0.440 & 0.0093 & 0.2989 & 9.0613 \\
-0.480 & 0.0085 & 0.7957 & 8.2000 \\
-0.540 & 0.0057 & 0.2150 & 8.5079 \\
-0.580 & 0.0038 & 0.7371 & 8.7724 \\
-0.600 & 0.0049 & 0.2516 & 8.9897 \\
\hline
\end{tabular}

Also, it was possible to evaluate the number of active nucleation sites for 3D process, see Table 2., In the potential range analyzed the $N$ values for Pt-UME-10 and Pt-UME-15 remain approximately constants, but for the Pt-UME-25, $N$ increase exponentially with the diminishing of the applied potential. Thus, considering the behavior of $D$ and $N$ values, it is possible to suggest that for the systems analyzed in the present work, there is an important contribution of radial diffusion onto the Pt-UME-10, while that Pt-UME-25 exhibits a planar microelectrode diffusion during the silver electrodeposition.

\section{CONCLUSIONS}

An electrochemical study about the silver electrodeposition onto Pt ultramicroelectrodes of 10,15 and $25 \mu \mathrm{m}$ of diameters from an aqueous solution containing $\mathrm{AgNO}_{3} 1 \mathrm{mM}+$ $\mathrm{NH}_{4} \mathrm{NO}_{3} 0.1 \mathrm{M}$ was conducted at overpotential conditions through voltamperometric and potentiostatic studies. The voltamperometric study indicates that the silver electrodeposition process is diffusional controlled. Also, the current density transients indicate the existence of two 2D nucleation and growth processes previous to the 3D nucleation and growth process.

Acknowledgments. Authors gratefully acknowledge financial support from CONACYT (project CB2015-257823) and to the Universidad Autónoma del Estado de Hidalgo. JACC acknowledges CONACYT for the scholarship granted for Doctoral studies LHMH acknowledges to the SNI for the distinction of his membership and the stipend received. 


\section{REFERENCES}

[1] R. Krishnan, S. Sriveeraraghavan, M. Deenadayalan, S. Jayakrishnan, R. Sekar, P. Jayachandran, Bull. Electrochem. 2000, 16, 136-139.

[2] H. Temam, L. Zeroual, A. Chala, S. Rahmane, C. Nouveau, Wiley-VCH Verlag, 2007, 4, 618-621. https://doi.org/10.1002/ppap.200731417

[3] J. Zoval, R. Stiger, P. Biernacki, R. Penner, J. Phys. Chem. 1996, 100, 837-844.

https://doi.org/10.1021/jp952291h

[4] R. Koda, K. Fukami, T. Sakka, Y. Ogata, Nanoscale Res. Lett. 2012, 7, 330.

https://doi.org/10.1186/1556-276X-7-330

[5] Q. Rayée, T. Doneux, C. Buess, Electrochim. Acta 2017, 237, 127-132.

https://doi.org/10.1016/j.electacta.2017.03.182

[6] J. Xie, Y. Zeng, X. Yang, X. Xu, Int. J. Electrochem. Sci. 2017, 12, 1690-1699.

https://doi.org/10.20964/2017.03.49

[7] S. Nineva, V. Dobrovolska, I. Krastev, Bulg. Chem. Commun. 2011, 43, 88-95.

[8] A. Never, L. Hallez, F. Touyeras, J. Hihn, Ultrason. Sonochem. 2018, 40, 60-71.

https://doi.org/10.1016/j.ultsonch.2017.02.03

[9] S. Kumaraguru, R. Pavul, J. Vijayakumar, S. Mohan, J. Alloys Compd. 2017, 693, 1143-1149.

https://doi.org/10.1016/j.jallcom.2016.10.027

[10] G. Zarkadas, A. Stergiou, G. Papanastasiou, J. Appl. Electrochem. 2004, 34, 607-615.

https://doi.org/10.1023/B:JACH.0000021920.59845.4c

[11] S. Sriveeraraghavan, R. Krishnan, S. Natarajan, Met. Finish. 1989, 87, 115-117.

[12] B. Zheng, L. P. Wong, L. Y. L. Wu, Z. Chen, Int. J. Electrochem. 2016, 2016, 4318178. https://doi.org/10.1155/2016/4318178

[13] A. Dimitrov, S. Hadzi, K. Popov, M. Pavlovic, V. Radmilovic, J. Appl. Electrochem. 1998, 28, 791-796. https://doi.org/10.1023/A:1003462924591

[14] P. Gay, P. Berçot, J. Pagetti, Surf. Coat. Technol. 2001, 140, 147-154.

https://doi.org/10.1016/S0257-8972(01)01043-X

[15] F. Ren, L. Yin, S. Wang, A. Volinsky, B. Tian, Trans. Nonferrous Met. Soc. China 2013, 23, 3822-3828. https://doi.org/10.1016/S1003-6326(13)62935-0

[16] B. Bozzini, G. Pietro, C. Mele, J. Electroanal. Chem. 2004, 563, 133-143. https://doi.org/10.1016/j.jelechem.2003.09.025

[17] A. Florea, A. Petică, L. Anică, T. Vişan, U.P.B. Sci. Bull. 2010, 72, 115-126.

[18] P. Sebastián, E. Vallés, E. Gómez, Electrochim. Acta 2013, 112, 149-158. https://doi.org/10.1016/j.electacta.2013.08.144
[19] K. Márquez, G. Staikov, J. Schultze, Electrochim. Acta 2003, 48, 875-882.

https://doi.org/10.1016/S0013-4686(02)00781-8

[20] M. Miranda-Hernández, I. González, J. Electrochem. Soc. 2004, 151, C220.

https://doi.org/10.1149/1.1646154

[21] M. Miranda-Hernández, I. González, N. Batina, J. Phys. Chem. B 2001, 105, 4214-4223. https://doi.org/10.1021/jp002057d

[22] X. Bu, S. Jian, L. Zhi, C. Guo, J. Electrochem.Soc. 2009, 156, D79. https://doi.org/10.1149/1.3046157

[23] P. Tulio, São Carlos, Universidade Federal de São Carlos, 1996.

[24] G. de Oliveira, M. Silva, C. Ivani, J. Mater. Sci. 2007, 42, 10164-10172. https://doi.org/10.1007/s10853-007-2102-z

[25] M. Peña, R. Celdran, R. Duo, J. Electroanal. Chem. 1994, 367, 85-92. https://doi.org/10.1016/0022-0728(93)03028-N

[26] R. Duo, R. Peña, R. Celdrán, J. Electroanal. Chem. 1996, 404, 99-104. https://doi.org/10.1016/0022-0728(95)04305-5

[27] C. Barin, A. Correia, L. Avaca, S. Machado, J. Braz. Chem. Soc. 2000, 11, 175-181. https://doi.org/10.1590/\$0103-50532000000200013

[28] A. Kandory, H. Cattey, L. Saviot, T. Gharbi, J. Vigneron, M. Fregnaux, A. Etcheberry, G. Herlem, J. Phys. Chem. C 2017, 121, 1129-1139. https://doi.org/10.1021/acs.jpcc.6b09913

[29] A. Correia, S. Machado, L. Avaca, J. Braz. Chem. Soc. 1994, 5, 173-177. https://doi.org/10.5935/0103-5053.19940030

[30] T. Berzins, P. Delahay. J. Am. Chem. Soc. 1953, 75, 555-559. https://doi.org/10.1021/ja01099a013

[31] Y. Saito, Rev. Polarogr. 1968, 15(6), 177-187. https://doi.org/10.5189/revpolarography.15.177

[32] K. Aoki, H. Takeuchi, J. Chen, T. Nishiumi. Rev. Polarogr. 2011, 57, 101-119.

https://doi.org/10.5189/revpolarography.57.101

[33] W. Torres-Hernández. Rev. Cienc. 2014, 18(1), 101110. https://doi.org/10.25100/rc.v18i1.473

[34] T. M. Braun, D. Josell, T. P. Moffat, J. Electrochem. Soc. 2020, 167, 082509 .

https://doi.org/10.1149/1945-7111/ab8e86

[35] E. Laborda, J. M. Olmos, F. Martínez-Ortiz, A. Molina, J. Solid State Electrochem. 2015, 19, 549-561. https://doi.org/10.1007/s10008-014-2620-y

[36] L. Zhi, X. Bu, C. Jin, S. Jian, C. Guo, J. Electroanal. Chem. 2009, 633, 207.

[37] B. Pollet, J. P. Lorimer, J. Y. Hihn, F. Touyeras, T. J. Mason, D. J. Walton, Ultrason. Sonochem. 2005, 5, 7. https://doi.org/10.1016/j.ultsonch.2004.05.006 
[38] B. R. Scharifker, G. Hills, Electrochim Acta 1983, 28, 879889. https://doi.org/10.1016/0013-4686(83)85163-9

[39] B. R. Scharifker, J. Mostany, J. Electroanal. Chem. 1984, 177, 13-23.

https://doi.org/10.1016/0022-0728(84)80207-7

[40] A. Bewick, M. Fleischmann, H. R. Thirsk. Trans. Faraday Soc. 1962, 58, 2200-2216.

https://doi.org/10.1039/tf9625802200
[41] B. R. Scharifker, J. Mostany, Electrochemical Nucleation and Growth, Wiley-VCH, Weinheim, Germany 2007.

https://doi.org/10.1002/9783527610426.bard020503

[42] M. Fleischmann, H. R. Thirsk in Advances in Electrochemistry and Electrochemical Engineering, Vol. 3, p. 123, (Ed.: P. Delahay), John Wiley \& Sons, Inc., New York, 1963. 